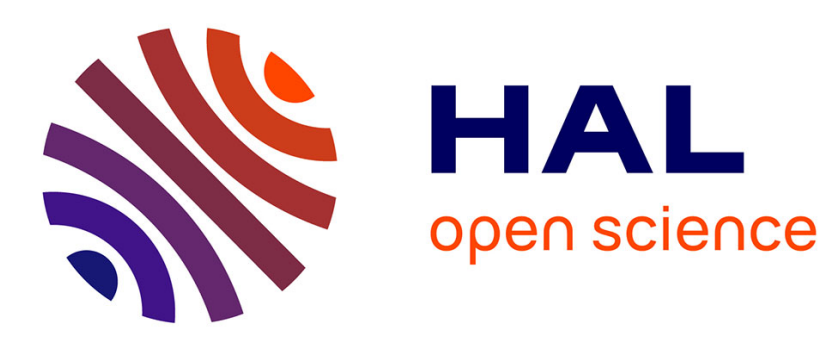

\title{
Modelling of ill-known requirements and integration in production planning
}

\author{
Romain Guillaume, Caroline Thierry, Bernard Grabot
}

\section{To cite this version:}

Romain Guillaume, Caroline Thierry, Bernard Grabot. Modelling of ill-known requirements and integration in production planning. Production Planning and Control, 2011, vol. 2, pp. 336-352. 10.1080/09537281003800900 . hal-00952725

\section{HAL Id: hal-00952725 \\ https://hal.science/hal-00952725}

Submitted on 27 Feb 2014

HAL is a multi-disciplinary open access archive for the deposit and dissemination of scientific research documents, whether they are published or not. The documents may come from teaching and research institutions in France or abroad, or from public or private research centers.
L'archive ouverte pluridisciplinaire $\mathbf{H A L}$, est destinée au dépôt et à la diffusion de documents scientifiques de niveau recherche, publiés ou non, émanant des établissements d'enseignement et de recherche français ou étrangers, des laboratoires publics ou privés. 


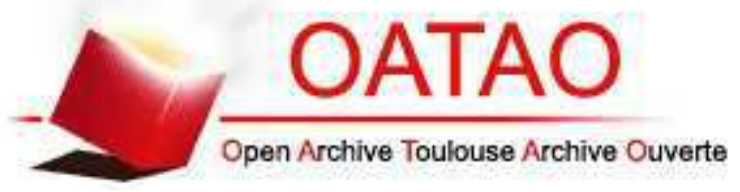

\section{Open Archive Toulouse Archive Ouverte (OATAO)}

OATAO is an open access repository that collects the work of Toulouse researchers and makes it freely available over the web where possible.

This is an author-deposited version published in: http://oatao.univ-toulouse.fr/ Eprints ID: 10928

To link to this article : DOI:10.1080/09537281003800900

http://dx.doi.org/10.1080/09537281003800900

\section{To cite this version:}

Guillaume, Romain and Thierry, Caroline and Grabot, Bernard Modelling of ill-known requirements and integration in production planning. (2011) Production Planning and Control, vol. 2 ( $\left.\mathrm{n}^{\circ} 4\right)$. pp. 336-352. ISSN 09537287

Any correspondence concerning this service should be sent to the repository administrator: staff-oatao@ listes-diff.inp-toulouse.fr 


\title{
Modelling of ill-known requirements and integration in production planning
}

\author{
ROMAIN GUILLAUME ${ }^{1,2}$, CAROLINE THIERRY $^{1}$, BERNARD GRABOT $^{2}$ \\ ${ }^{1}$ UNIVERSITE DE TOULOUSE-IRIT \\ 5, Allées A. Machado, F-31058 Cedex 1 \\ Romain.Guillaume@irit.fr \\ thierry@univ-tlse2.fr \\ ${ }^{2}$ UNIVERSITE DE TOULOUSE, INPT, LGP-ENIT, \\ 47 Avenue d'Azereix, \\ BP 1629, F-65016 TARBES CEDEX \\ bernard@enit.fr
}

\begin{abstract}
Making decisions on the base of uncertain forecasts is one of the key challenges for efficient Supply Chain Management. This article suggests the use of the theory of possibility for building a procurement plan on the base of ill-known requirements. These requirements, expressed in quantities by date, may come from various sources: forecasts or orders for instance. The possible types of imperfection pervading requirement are analysed and a unified representation model is suggested. A method is then described for calculating a plausible demand by period without loss of information; it is illustrated on an example in the last section.
\end{abstract}

Keywords - requirement, demand, imprecision, uncertainty, theory of possibility.

\section{INTRODUCTION}

Today's industrial context is characterised by an increased uncertainty on the final customer's demand. In many supply chains, and especially in the aeronautical industry, the supply times are much longer than the manufacturing times. In this context, an important challenge is to manage the procurement process in spite of the uncertainty on the demand.

Collaborative processes aim at reducing this supply risk. Vendor Management Inventory $\left(\mathrm{VMI}^{\circledR}\right)$ (Marques et al., 2008) and Collaborative Planning, Forecasting and Replenishment (CPFR ${ }^{\circledR}$ ) (Ireland and Crum, 2005) are for instance widely used in an industrial context. These techniques aim at creating short and reactive decision loops between customers and suppliers in order to cope with the growing uncertainty on demand forecasting, due to the shortening of the product life cycle and to customers' versatility. Nevertheless, they can only deal with quite standard requirements, which is for instance the case in the automotive industry. Taking into account the uncertainty of the demand in the planning processes can be an alternative solution for more specific requirements, e.g. in the spatial and aeronautical industry for which the problem is still critical. 
In this study is considered a dyadic elementary link of a supply chain, involving two actors (customer/supplier). Within these two partners, it will be shown that an uncertain demand can be considered in order to build a "fuzzy" procurement plan, firstly internally processed then transmitted to the upstream suppliers. Like a classical one, this procurement plan is expressed in quantities per periods, but does not only describe one (most plausible) situation, but a set of situations, with a quantification of their possibility of occurrence. It should then allow to make more informed decisions concerning the risk taken by ordering a given quantity.

The article is organized as follows: section 2 presents a state of the art on the application of possibility theory to production planning problems. The basis of possibility theory and the problem of representation of imperfect information are introduced in the following section, whereas a way to represent "imperfection" (uncertainty, imprecision...) on the requirements is proposed in section 3 . The integration in the Material Requirement Planning of imperfect requirements, using the suggested method, is described in section 4. The approach is illustrated on an example in section 5.

\section{LiTERATURE REVIEW}

In a manufacturing context, production planning aims at optimizing the use of the resources to fulfil the customers' demand. Usually, forecasts are estimated on the base of historical data, and allow to build a Sales and Operation Plan, implicitly considered as certain but periodically revised (SOP step of the MRP (Manufacturing Resource Planning) method). A Master Production Schedule then details the SOP, listing quantities of required products per periods of time. Using the bill of materials, these "independent" requirements are then used to generate requirements on components, also by periods. In an uncertain context, the problem is to build a feasible requirement plan on the base of an ill-known demand.

In that purpose, a large part of the literature focuses on rolling horizon planning methods: an initial planning is periodically updated in order to take into account the most recent knowledge on the demand. Strategies like adjusting the re-planning horizon size (Galasso et al., 2009), or freezing a part of the plan (Zhao and Xie, 1998) may be used in that purpose. On the other hand, production planning under uncertainty aims at modelling this uncertainty in order to provide the decision maker with a richer view on the various possible situations which may arise. Within this strategy, stochastic and possibilistic models have been mainly used to represent imperfect data. Stochastic models need a huge 
amount of historical data, and require that the context in which the data have been collected remains still valid in the future. Since this is more and more rare, we focus here on the case when it is difficult to use such methods. In that case, uncertainty may often be modelled on the base of the human expertise. Fuzzy logic and theory of possibility have shown their interest for representing subjective information and some works have already been performed on the representation of a subjectively assessed uncertainty on the demand.

Within these works, it is important to distinguish production planning under flexible constraints from production planning with ill-known parameters (Dubois et al., 2003). In the literature on production planning under flexible constraints (Mula et al., 2007, Jamalnia and Soukhakian, 2009), fuzziness models a level of satisfaction of constraints expressed by imprecise terms (often in natural language), or a degree of tolerance (Bellman and Zadeh, 1970). Several surveys (Kacprzyk and Orlovski, 1987, Delgado et al., 1994, Baykasoglu and Göçken, 2008) show how fuzziness can in that case be accommodated with linear programming.

In the literature on production planning under uncertainty, fuzziness is used for modelling the level of possibility that an event may occur. Both approaches refer to the possibility theory (Zadeh, 1978, Dubois and Prade, 1988) and to decision under fuzzy uncertainty (Dubois et al., 2001).

Production planning under uncertainty based on possibility theory may allow to compute a supply plan considering an uncertain demand, modelled by possibility distributions. Some authors suggest to make decisions on the base of a fuzzy plan, while others use defuzzification techniques for obtaining a crisp plan. In the first category can be found (Fargier and Thierry, 2000), in which the MPS (Master Production Schedule) considers an uncertain demand. A method is proposed to support subcontracting decisions or negotiation with the customer. In the same way, in (Grabot et al., 2005), the imperfection on the customer's demand is taken into account in the Manufacturing Resource Planning through a method called F-MRP (Fuzzy-MRP), resulting in a "fuzzy plan".

Another solution is to model first the uncertain plan, then to defuzzify in order to obtain a crisp equivalent demand (demand after defuzzification) (Niu and Dartnall, 2008, Liang, 2008, Peidro et al., 2009).

An alternative is to build a plan which takes into account a level of possibility, necessity or credibility in order to guarantee or optimise a "level of chance" that the plan is feasible. In (Lan et al., 2009), the chance that the inventories will be superior to zero is guaranteed by the constraints while in (Sun and 
Liu, 2008), the objective to minimize is the chance than the cost function is inferior to a given threshold. In (Aliev et al., 2007), the objective function to minimize is the chance that the demand will not be satisfied, combined with the profit.

(Liu, 2009) presents a set of other models for optimisation under uncertainty with fuzzy parameters, which could be used in supply chain planning.

When dates related to precise orders and durations of tasks are considered, scheduling under uncertainty may result in a fuzzy schedule (Chen and Huang, 2006, Balasubramanian and Grossmann, 2003). These references are summarised in Table 1.

Table 1. Classification of previous works

\begin{tabular}{|l|l|l|}
\hline References & Use of fuzziness & type of model \\
\hline $\begin{array}{l}\text { (Jumaln } \text { et al., 2007) } \\
\text { 2009) }\end{array}$ & Flexible constraints & planning \\
\hline $\begin{array}{l}\text { (Fargier and Thierry, 2000) } \\
\text { (Grabot et al., 2005) }\end{array}$ & Integration of uncertainty & planning \\
\hline $\begin{array}{l}\text { (Niu and Dartnall, 2008) } \\
\text { (Liang, 2008) } \\
\text { (Peidro } \text { et al., 2009) }\end{array}$ & $\begin{array}{l}\text { Defuzzification } \\
\text { then optimisation }\end{array}$ & planning \\
\hline $\begin{array}{l}\text { (Lan } \text { et al., 2009) } \\
\text { (Sun and Liu, 2008) } \\
\text { (Aliev et al., 2007) }\end{array}$ & Optimisation \\
\hline $\begin{array}{l}\text { (Chen and Huang, 2006) } \\
\text { (Balasubramanian } \\
\text { Grossmann, 2003) }\end{array}$ & under uncertainty & Optimisation \\
\hline
\end{tabular}

Even if possibility theory has been intensively used for modelling uncertainty in planning processes, it is interesting to notice that none of these methods addresses the basic industrial problem in its more generic form: if the imperfection of the demand concerns both the quantities (i.e. the level of a requirement may change) and the dates (the requirement may be advanced or postponed), finding how many components may be required in a given period in order to fulfil this demand becomes a complex task. In order to address this problem, this article first suggests a method aiming at characterising and representing "uncertainty" (imperfection, uncertainty and imprecision) on the independent requirements, then shows how to turn these "imperfectly known" requirements into dependent requirements (a supply plan composed of required quantities of components by periods), in a way which stays as close as possible to industrial practices. This supply plan will be considered for deciding the quantities ordered to the upstream partners of the supply chain. 


\section{BASIC FRAMEWORK}

The objective of this section is to position the various concepts covering the vague notion of "imperfect information", and to present some models allowing to represent them. Besides are introduced the main results of the theory of possibility which will be used afterwards.

\subsection{Definition of imperfection}

Even if the word "uncertainty" is commonly used, a distinction has to be made between several concepts: uncertainty, imprecision and incompleteness. The term "imperfection" will be used to gather these three concepts, as suggested in (Bouchon-Meunier, 1995).

- Uncertainty occurs when it is not possible to state whether a particular statement is definitely true or false.

- Imprecision denotes the impossibility to enounce a piece of knowledge including crisp values in a sure manner.

- Incompleteness means in most cases that an information source does not contain full information about the values of the attributes of the real-world it describes (some properties may be missing from the description).

As stated above, two types of mathematic models can represent imperfect data: stochastic and possibilistic models (Dubois and Prade, 2006). Because of the highly dynamic context of today's manufacturing, we consider in this article the case when no previous observation is available for building a stochastic model. In that case, possibility theory has shown its interest for modelling uncertainty on the base of expert knowledge.

\subsection{Representation of imperfection}

\subsubsection{Representation of uncertainty}

For each event $A$ from a subset $S$, the uncertainty may be evaluated through two levels: the possibility $\Pi(A)$, denoting to what extent the occurrence of event $A$ if possible, and the certainty $\mathrm{N}(A)$, denoting to what extend the occurrence of event $A$ is certain, with:

$$
\forall A \subseteq S, \mathrm{~N}(A) \leq \prod(A)
$$

and

$$
\forall A \subseteq S, \mathrm{~N}(A)=1-\Pi(\bar{A})
$$


If the occurrence of $A$ is certain $\Pi(A)=1$ and $\mathrm{N}(A)=1$; if the occurrence of $A$ is impossible: $\Pi(A)=0$ and $\mathrm{N}(A)=0$. If there is no knowledge available: $\Pi(A)=1$ and $\mathrm{N}(A)=0$ (the event is fully possible but not necessary at all).

\subsubsection{Representation of imprecision}

An imprecise information may be defined as $v \in A$ where $A$ is a subset of $S$ which contains more than one element. The imprecision may be expressed by a disjunction of values (Dubois and Prade, 2006) defined by a possibility distribution on $S$. $v \in A$ means that all values from $v$ outside $A$ are supposed to be impossible.

A possibility distribution $\pi_{v}$ of $v$ quantifies the plausibility of the information $v . \pi_{v}$ is a function of $S$ in $L$ such as $\forall s \in S, \pi_{v}(s) \in L$, and $\exists s, \pi_{v}(s)=1$ with $v$ denoting an ill-known value in $S$, and $L$ the scale of plausibility ([0,1] for the theory of possibility).

\subsubsection{Representation of uncertainty and imprecision}

Information can be pervaded with both uncertainty and imprecision. Uncertainty and imprecision is denoted by $v \in A U B$ where $A$ and $B$ are two disjoints subset of $S$, one expressing the possibility that the event does not occur, the other defining the (possibly imprecise) content of the event if it occurs. The possibility distribution associated to the information $v \in A U B$ is noted $\pi(v)$ with:

$$
\begin{aligned}
& \Pi(A)=\max (\pi(v) \mid v \in A) \\
& \Pi(B)=\max (\pi(v) \mid v \in B)
\end{aligned}
$$

These two events being mutually exclusive, they are characterised by relation (4):

$$
\begin{aligned}
& \max (\Pi(A), \Pi(B))=\max (\Pi(A), \Pi(\bar{A})) \\
& =\max (\Pi(A), 1-N(A))=1
\end{aligned}
$$

\subsection{Basic Operations}

In order to describe the events by possibility distributions, trapezoidal distributions (cf. Figure 1), denoted $(a, b, c, d, h)$, can be used without an important loss of generality. Indeed, these sets intend to model an expertise which suggests a global shape rather than a precise function.

For performing a Material Requirement Planning, we need first to define an operator of addition, which is made according to (Zadeh, 1978) and (Dubois and Prade, 1988). 


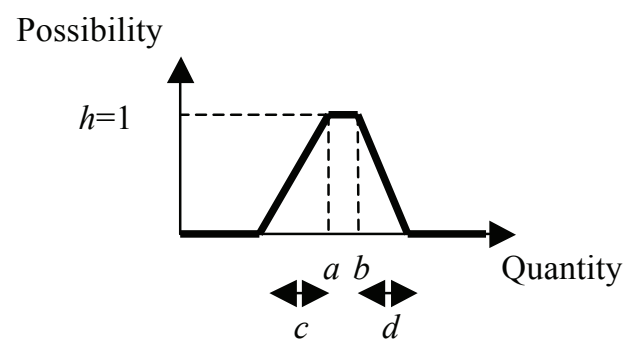

Figure 1. Trapezoidal distribution of possibility

A possibility distribution $\pi_{\mathrm{x}}$ is defined as the membership function $\mu_{A}$ of $A, A$ being defined as a fuzzy set, i.e. a set of elements $x$ which belong to $A$ with a degree $\mu_{A}(x)$.

The sum of two trapezoidal distributions $A_{i}$ and $A_{j}$ defined by the quintuplets $A_{i}\left(a_{i}, b_{i}, c_{i}, d_{i}, h_{i}\right)$ and $A_{j}$ $\left(a_{j}, b_{j}, c_{j}, d_{j}, h_{j}\right)$ is defined by (Dubois and Prade, 1988):

$$
A_{i} \oplus A_{j}=(a, b, c, d, h)
$$

with:

$$
\begin{aligned}
& h=\min \left(h_{i}, h_{j}\right) \\
& c=h \cdot\left(\frac{c_{i}}{h_{i}}+\frac{c_{j}}{h_{j}}\right) \\
& d=h \cdot\left(\frac{d_{i}}{h_{i}}+\frac{d_{j}}{h_{j}}\right) \\
& a=a_{i}+a_{j}-c_{i}-c_{j}+c \\
& b=b_{i}+b_{j}+d_{i}+d_{j}-d
\end{aligned}
$$

If $A=A_{1} \cup A_{2} \ldots \cup A_{n}$ and $B=B_{1} \cup B_{2} \ldots \cup B_{p}$ with $A_{i}$ and $B_{j}$ defined by the quintuplets $\left(a_{i}, b_{i}, c_{i}, d_{i}\right.$, $\left.h_{i}\right)$ and $\left(a_{j}, b_{j}, c_{j}, d_{j}, h_{j}\right)$

$$
A \oplus B=\bigcup_{i=1 . . . n, j=1 . . p} A_{i} \oplus B_{j}
$$

Calculating gross requirements consists in allocating quantities of components to periods. If the quantity is imprecise or uncertain, we need to compute the possibility and the necessity that a set belongs to an interval.

The possibility of the event " $x \in F$ ", denoted $\Pi(x \in F)$, is the degree of intersection between $A$ and $F$, defined by equation (7). The dual measure of necessity of " $x \in F$ ", denoted $\mathrm{N}(x \in F)$, evaluates to what extent " $x \in F$ " is certainly true. It is defined by equation (8).

$$
\begin{gathered}
\Pi(x \in F)=\sup _{u}\left(\min \left(\mu_{A}(u), \mu_{F}(u)\right)\right) \\
\mathrm{N}(x \in F)=\inf _{u}\left(\max \left(1-\mu_{A}(u), \mu_{F}(u)\right)=1-\Pi\left(x \in F^{c}\right)\right)(8)
\end{gathered}
$$

where $F^{c}$ denotes the fuzzy complement of $F\left(\mu_{F}=1-\mu_{F^{C}}\right)$ 
If $x$ is a real variable and $A$ a fuzzy interval, tmin and tmax represent respectively the minimum and the maximum limit of the interval (see Figure 2). The possibility that $\mathrm{x}$ is between the limits of the interval is given by equation (9):

$$
\Pi(t \min \leq x \leq t \max )=\Pi(x \in t)=\sup _{t \min \leq u \leq t \max }\left(\mu_{A}(u)\right)
$$

On the opposite, the possibility that $\mathrm{x}$ does not belong to the interval is given by equation (10):

$$
\Pi(x \notin t)=\max \left(\Pi(x \in(-\infty, t \min ]), \Pi(x \in[t \max ,+\infty))=\max \left(\sup _{u \leq t \min }\left(\mu_{A}(u)\right), \sup _{t \max \leq u}(\mu(A))\right)\right.
$$

The necessity that $\mathrm{x}$ belongs to the interval is given by (11):

$$
\mathrm{N}(t \min \leq x \leq t \max )=\mathrm{N}(x \in t)=1-\Pi(x \notin t)
$$

The results of equations (9) to (11) are illustrated in Figure 2.
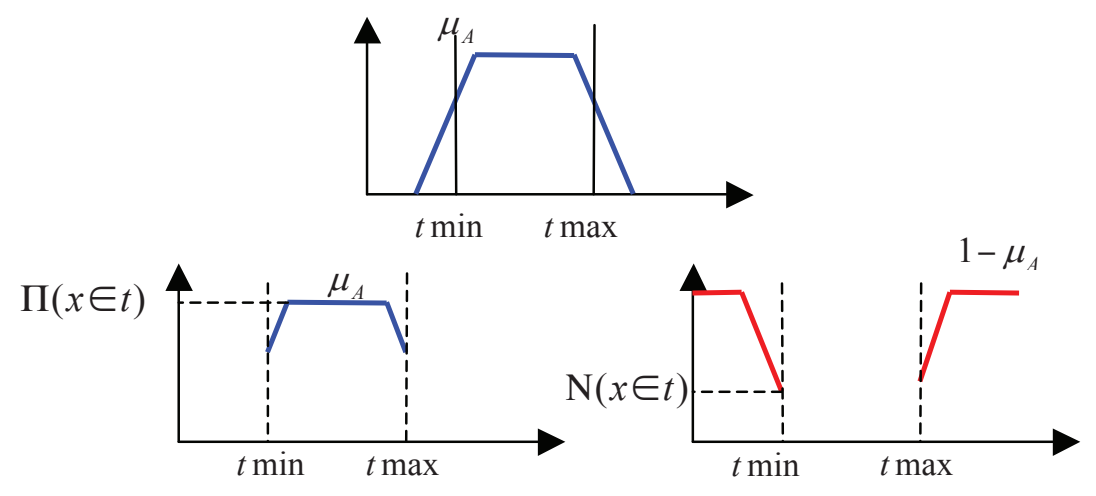

Figure 2. Computation of possibility and necessity levels that an element belongs to an interval It will be shown in next section how these basic operations allow to build a possible gross requirement plan.

\section{Calculation of the Gross ReQuirements}

Figure 3 illustrates the process allowing to compute the gross requirements. Ill-known requirements (coming from forecasts or orders) are firstly considered as input of the process ((1) in Figure 3). These requirements are modelled through possibility distributions (step (2)). The result of this step is that each requirement is now modelled by a fuzzy quantity on a fuzzy date (3). The possibility and necessity that each quantity belongs to a period of the plan is then computed (4). Since a quantity may have non null possibilities to belong to several periods, it is then possible to define various scenarios for each requirement (depending on the period on which its occurrence is considered) (5). The decision maker will then suggest criteria for extracting one or several scenarios (most possible, optimistic, pessimistic, etc.) (6). These criteria are used to filter the possible scenarios (7). The decision maker can then make a decision on the base of the provided information. 


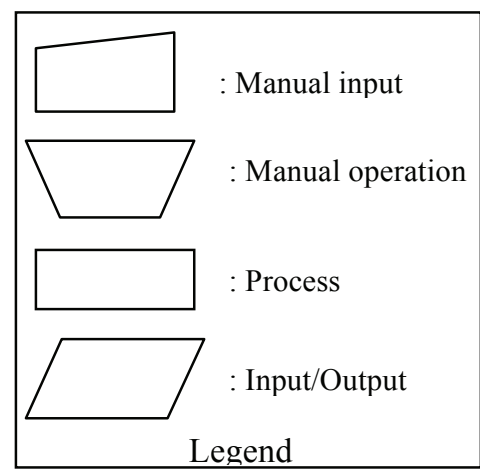

1. Ill-known requirements 6. Criteria of the
decision maker

5. Set of scenarios for each

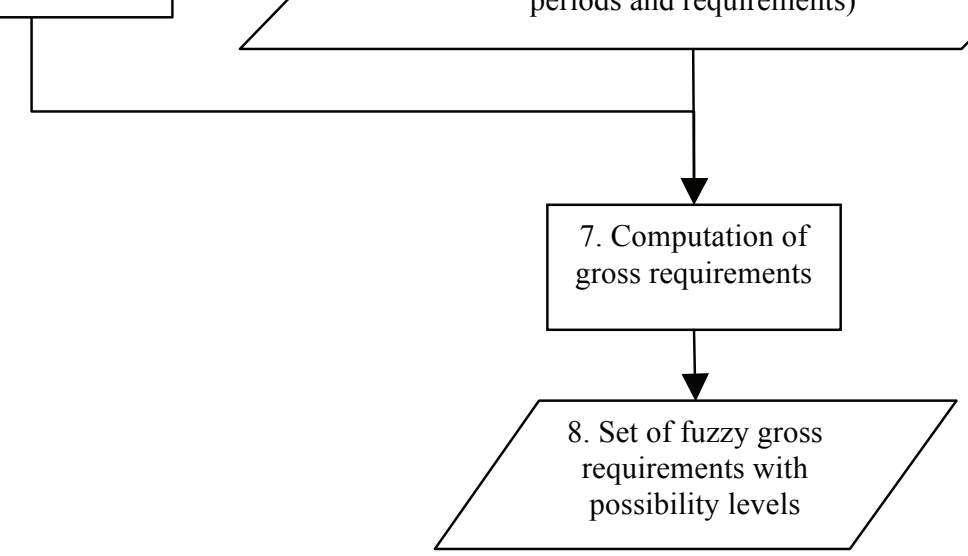

Figure 3. Flowchart of the computation of gross requirements

These steps will now be explained with more details.

\subsection{Representation of ill-known requirements}

A requirement $o$ is characterised by a quantity $Q_{o}$ and a date (due date) $\tau_{o}$.

\subsubsection{Types of imperfections}

The imperfection on the requirements may be on the requirement itself, i.e. the requirement can be uncertain. For example, if the requirement comes from forecasts, it can be confirmed or cancelled through time. The imperfection may also affect the attributes of the requirement: the quantity or the 
date. For each attribute, the two different types of imperfections defined above (imprecision and uncertainty) can be considered.

\subsubsection{General model of imprecision on the requirements}

It is possible to define the imprecision of a quantity by two intervals: one defining the most possible values, and the second all the possible values (Grabot et al., 2005) or to infer a possibility distribution from very few measurements (Mauris, 2008), then to compute the trapezoidal fuzzy number which approximates this possibility distribution (Grzegorzewski, 2008). In order to be consistent with the expert knowledge available in the companies, we suggest to represent the imperfection (uncertainty and imprecision) on the requirements using two fuzzy sets:

- the first fuzzy set represents the imperfection (uncertainty and imprecision) on the required quantity, and the uncertainty of the occurrence of the requirement itself (possibility that the required quantity is $0)$

- the second fuzzy set represents the imperfection on the due date.

The considered fuzzy sets are so defined as unions of trapezoidal fuzzy sets, which preserves the generality of the representation. In the following figures are introduced the various types of elementary sets used to represent the requirement pervaded by different types of imperfection.

Figure 4 represents a precise value (a), of possibility $h$. Figure 5 shows an imprecise quantity with a maximum possibility equal to $h$. Figure 6 represents the uncertainty on the occurrence of a requirement; the value zero (which means that the requirement is cancelled) has a possibility level equal to $h^{\prime}$.

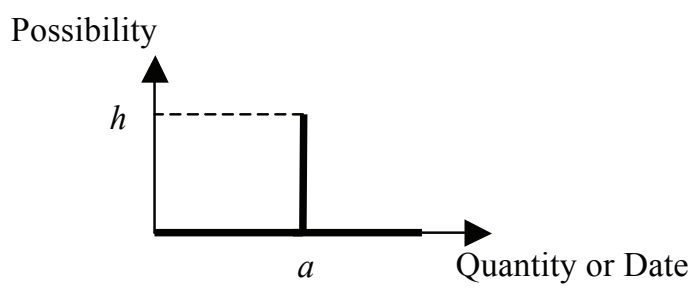

Figure 4. Representation of $(a ; a ; 0 ; 0 ; h)$ 
Possibility

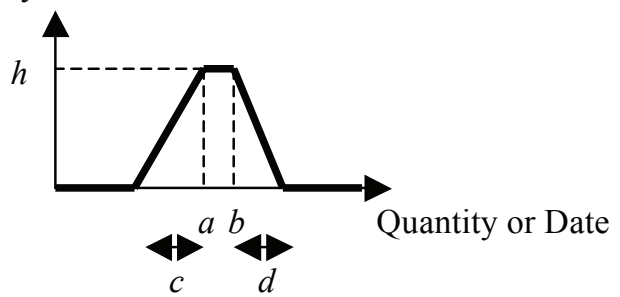

Figure 5. Representation of $(a ; b ; c ; d ; h)$

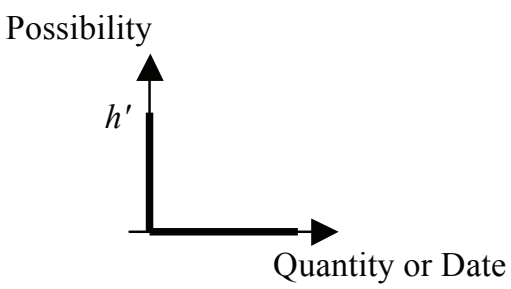

Figure 6. Representation of $\left(0 ; 0 ; 0 ; 0 ; h^{\prime}\right)$

These figures do not yet define consistent requirements, since the definition of a possibility distribution sets the constraint that $\max (\pi(A))=1$ (at least one event has to be completely possible), which is not the case for these sets if $h$ and $h^{\prime} \neq 1$. In order to define an imprecise requirement which cancellation is more plausible than its confirmation, the union of the fuzzy sets of Figure 5 and 6 has to be defined, with (for instance) $h=0.8$ and $h^{\prime}=1$.

Table 2. Representation a of quantity

\begin{tabular}{|c|c|c|c|c|}
\hline \multicolumn{3}{|c|}{ Certain quantity } & \multicolumn{2}{|c|}{ Uncertain Quantity } \\
\hline & Precise quantity & Imprecise quantity & Precise quantity & Imprecise quantity \\
\hline $\begin{array}{c}\text { Certain } \\
\text { requirement }\end{array}$ & $(q a ; q a ; 0 ; 0 ; 1)$ & $(q a ; q b ; q c ; q d ; 1)$ & $\begin{array}{c}\bigcup_{i=1}^{n}\left(q a_{i} ; q a_{i} ; 0 ; 0 ; q h_{i}\right) \\
\max _{j=1}^{n}\left(h_{j}\right)=1\end{array}$ & $\begin{array}{c}\bigcup_{i=1}^{n}\left(q a_{i} ; q b_{i} ; q c_{i} ; q d_{i} ; q h_{i}\right) \\
n \\
\max _{j=1}^{n}\left(h_{j}\right)=1\end{array}$ \\
\hline $\begin{array}{c}\text { Uncertain } \\
\text { requirement }\end{array}$ & $\begin{array}{c}(q a ; q a ; 0 ; 0 ; q h) U \\
\left(0 ; 0 ; 0 ; 0 ; h^{\prime}\right) \\
\quad \max \left(h^{\prime}, q h\right)=1\end{array}$ & $\begin{array}{c}(q a ; q b ; q c ; q d ; q h) U \\
\left(0 ; 0 ; 0 ; 0 ; h^{\prime}\right) \\
\quad \max \left(h^{\prime}, q h\right)=1\end{array}$ & $\begin{array}{l}\bigcup_{i=1}^{n}\left(q a_{i} ; q a_{i} ; 0 ; 0 ; q h_{i}\right) \\
\cup\left(0 ; 0 ; 0 ; 0 ; h^{\prime}\right) \\
\quad \max _{j=1}\left(h_{j}, h^{\prime}\right)=1\end{array}$ & $\begin{array}{l}\bigcup_{i=1}^{n}\left(q a_{i} ; q b_{i} ; q c_{i} ; q d_{i} ; q h_{i}\right) \\
\cup\left(0 ; 0 ; 0 ; 0 ; h^{\prime}\right) \\
\quad \max _{j=1}\left(h_{j}, h^{\prime}\right)=1\end{array}$ \\
\hline
\end{tabular}

Table 2 summarises the way the different models can be combined in order to define the imperfections on the quantities, $q a, q b \ldots$ being the values allowing to define the fuzzy number which represents the quantities.

Table 3 summarises the combinations of models which may represent the various imperfections on the dates. The values allowing to represent the fuzzy numbers modelling a date are denoted $\tau a, \tau b \ldots$ 
Table 3. Representation of the requirement date

\begin{tabular}{|c|c|c|c|c|}
\hline \multicolumn{3}{|c|}{ Certain requirement date } & \multicolumn{2}{|c|}{ Uncertain requirement date } \\
\hline & Precise date & Imprecise date & Precise date & Imprecise date \\
\hline $\begin{array}{l}\text { Certain } \\
\text { requirement }\end{array}$ & $(\tau a ; \tau a ; 0 ; 0 ; 1)$ & $(\tau a ; \tau b ; \tau c ; \tau d ; 1)$ & $\begin{array}{c}\bigcup_{i=1}^{n}\left(\tau a_{i} ; \tau a_{i} ; 0 ; 0 ; \tau h_{i}\right) \\
\max _{j=1}^{n}\left(\tau h_{j}\right)=1\end{array}$ & $\begin{array}{c}\bigcup_{i=1}^{n}\left(\tau a_{i} ; \tau b_{i} ; \tau c_{i} ; \tau d_{i} ; \tau h_{i}\right) \\
\max _{j=1}^{n}\left(\tau h_{j}\right)=1\end{array}$ \\
\hline $\begin{array}{l}\text { Uncertain } \\
\text { requirement }\end{array}$ & $\begin{array}{l}(\tau a ; \tau a ; 0 ; 0 ; \tau h) \\
\quad \max \left(h^{\prime} ; \tau h\right)=1\end{array}$ & $\begin{array}{l}(\tau a ; \tau b ; \tau c ; \tau d ; \tau h) \\
\quad \max \left(h^{\prime} ; \tau h\right)=1\end{array}$ & $\begin{array}{c}\bigcup_{i=1}^{n}\left(\tau a_{i} ; \tau a_{i} ; 0 ; 0 ; \tau h_{i}\right) \\
\max _{j=1}^{n}\left(\tau h_{j}\right)=1\end{array}$ & $\begin{array}{c}\bigcup_{i=1}^{n}\left(\tau a_{i} ; \tau b_{i} ; \tau c_{i} ; \tau d_{i} ; \tau h_{i}\right) \\
n \\
\max _{j=1}\left(\tau h_{j}\right)=1\end{array}$ \\
\hline
\end{tabular}

\subsection{Material requirement planning}

Models of requirements based on unions of two sets have been introduced. One of the sets represents the imperfection on the quantity and the uncertainty on the requirement, whereas the other represents the imperfection on the date. The problem is now to compute a gross requirement, which is a set of quantities expressed for each period of the horizon.

Different scenarios can be deduced from the elementary requirements expressed as in Tables 2 and 3 , since a requirement may belong to different periods (according to the imprecision on its date) and may be composed of different quantities (according to its uncertainty and imprecision).

To compute the gross requirements, let us define the following notations:

Index

$o$ : requirement with $o \in[1, \mathrm{O}]$

$t$ : period with $t \in[1, \mathrm{~T}]$

$j_{o}$ : index of fuzzy set of requirement $o$ with $j_{o} \in\left[1, \mathrm{~J}_{\mathrm{o}}\right]$

$u_{o}$ : period in which the requirement $o$ could exist with $u_{o} \in\left[\mathrm{U}_{\mathrm{ao}}, \mathrm{U}_{\mathrm{zo}}\right]$

$c$ : number of combination with $c \in[1, \mathrm{C}]$

\section{Variables}

$Q_{o}$ : possible required quantity of requirement $o$,

$\tau_{o}$ : possible date of requirement $o$,

$E_{o, j_{o}, u_{o}, t}:$ quantity for period $t$ of the fuzzy set $j_{o}$ of requirement $o$ which belongs to period $u_{o}$

$S_{o, j_{o}, u_{o}}$ : scenario in which the fuzzy set indexed by $j_{o}$ of the requirement $o$ belongs to period $u_{o}$

$D_{c, t}:$ gross requirement quantity for combination $c$ for period $t$. 


\subsubsection{Design of requirement scenarios}

For each requirement, the number of elementary scenarios is equal to the number of periods to which the requirement may belong. As a first step, the possibility for each requirement $o$ to belong to each period $t$ is calculated (equation 12). This means that the requirement exists in a given period $t$ with a given level of possibility:

$$
\Pi\left(\tau_{o} \in t\right)=\max \left(\pi\left(\tau_{o}\right) \mid \tau_{o} \in t\right)
$$

As a second step, for each requirement $o$, the set $\boldsymbol{Z}_{0}$ of the periods on which the requirement may occur is selected (equation 13):

$$
\boldsymbol{\gamma}_{o} / u_{o} \in \boldsymbol{\gamma}_{o} \text { if } \Pi\left(\tau_{o} \in u_{o}\right) \neq 0 \quad \text { with } u_{o} \in\left[\mathrm{U}_{\mathrm{ao}}, \mathrm{U}_{\mathrm{zo}}\right](13)
$$

Example: let us consider a requirement $A$ on $\tau_{A}=(6 ; 6 ; 1 ; 2 ; 1)$ and period $1=$ $[0 ; 7[$, period $2=[7 ; 14[$ and period $3=[14 ; 21[$.

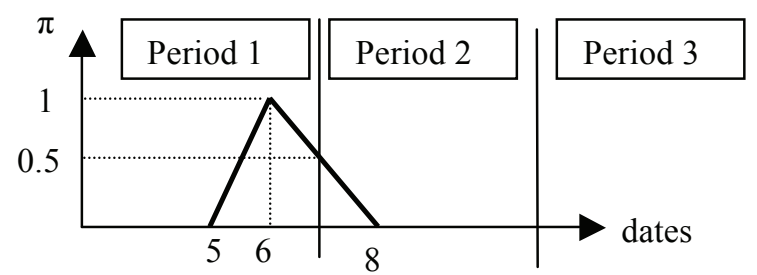

Figure 7. Representation of $\tau_{A}$

$$
\begin{aligned}
& \Pi\left(\tau_{A} \in 1\right)=\max \left(\pi\left(\tau_{A}\right) \mid \tau_{A} \in[0 ; 7[)=1\right. \\
& \Pi\left(\tau_{A} \in 2\right)=\max \left(\pi\left(\tau_{A}\right) \mid \tau_{A} \in[7 ; 14[)=0.5\right. \\
& \Pi\left(\tau_{A} \in 3\right)=\max \left(\pi\left(\tau_{A}\right) \mid \tau_{A} \in[14 ; 21[)=0\right. \\
& \text { So } \boldsymbol{\gamma}_{A}=\{1 ; 2\}
\end{aligned}
$$

The requirement belongs to period 1 with a degree of possibility 1 , and to period 2 with a degree of possibility 0.5 (see Figure 7).

In the third step, the required quantity of the different scenarios is calculated. It can be noticed that the possibility degree that a requirement $o$ belongs to period $t\left(\Pi\left(\tau_{o} \in u_{o}\right)\right)$ expresses than the requirement can exist in this period, but also that it cannot exist in other periods of $\boldsymbol{7}_{0}$. 
Let us denote $Q_{o}=\bigcup_{j_{o}=1}^{J_{o}} A_{o, j_{0}}$ the quantity of the requirement, with $j_{o}$ the index of the fuzzy set (imprecise value); $j_{o} \in\left[1, \mathrm{~J}_{o}\right]$. The different scenarios $w_{o}$ of requirement $o$ can be defined by $w_{o}=\left(j_{o} ; u_{o}\right)$.

Table 4 represents the values of the required quantities for each period, by taking into account that the requirement can exist in one and only one period of the horizon.

$U_{o}$ being the number of periods of $\boldsymbol{7}_{o}$, we have $S_{o}=U_{o} \times J_{o}$ scenarios for each requirements $o$.

Let us denote $S_{o, j_{o}, u_{o}}=\bigcup_{t \in T_{o}} E_{o, j_{0}, u_{o}, t}$

Table 4. Representation of the possible quantities

\begin{tabular}{|c|c|c|c|}
\hline \multicolumn{2}{|c|}{$\begin{array}{l}\text { Quantity of requirement in } \\
\text { other periods than } u_{o}\end{array}$} & \multicolumn{2}{|c|}{ Quantity of requirement in period $u_{o}$} \\
\hline \multirow[t]{3}{*}{$U_{a o}$} & \multirow{3}{*}{$\begin{array}{l}\subseteq \subseteq U_{a o} \text { with } \\
\Pi\left(\tau_{o} \in U_{a o}\right) \\
\quad \Downarrow \\
\bar{B}_{o, v, u_{a o}} \\
=\left(0 ; 0 ; 0 ; 0 ; \Pi\left(\tau_{o} \in U_{a o}\right)\right) \\
\forall v \in \boldsymbol{7}_{o}-\left\{U_{a o}\right\}\end{array}$} & $j_{o}=1$ & $B_{o, 1, U_{a o}}=\left(a_{A_{o, 1}} ; b_{A_{o, 1}} ; c_{A_{o, 1}} ; d_{A_{o, 1}} ; h_{A_{o, 1}} \times \Pi\left(\tau_{o} \in u_{a o}\right)\right)$ \\
\hline & & $\cdots$ & \\
\hline & & $j_{o}=J_{o}$ & $B_{o, J_{o}, U_{a o}}=\left(a_{A_{o, j_{o}}} ; b_{A_{o, j_{o}}} ; c_{A_{o, j_{o}}} ; d_{A_{o, j_{o}}} ; h_{A_{o, j_{o}}} \times \Pi\left(\tau_{o} \in u_{a o}\right)\right)$ \\
\hline & $\ldots$ & & \\
\hline \multirow[t]{3}{*}{$U_{z o}$} & \multirow{3}{*}{$\begin{array}{c}o \subseteq U_{z o} \text { with } \\
\Pi\left(\tau_{o} \in U_{z o}\right) \\
\Downarrow \\
\bar{B}_{o, v, U_{z o}}=. .\end{array}$} & $j_{o}=1$ & $B_{o, 1, U_{a o}}=\left(a_{A_{o, 1}} ; b_{A_{o, 1}} ; c_{A_{o, 1}} ; d_{A_{o, 1}} ; h_{A_{o, 1}} \times \Pi\left(\tau_{o} \in u_{a o}\right)\right)$ \\
\hline & & $\cdots$ & \\
\hline & & $j_{o}=J_{o}$ & $B_{o, J_{o}, U_{a o}}=\left(a_{A_{o, j_{o}}} ; b_{A_{o, j_{o}}} ; c_{A_{o, j_{o}}} ; d_{A_{o, j_{o}}} ; h_{A_{o, j_{o}}} \times \Pi\left(\tau_{o} \in u_{a o}\right)\right)$ \\
\hline
\end{tabular}

Example: let us consider the same requirement $A$

$Q_{A}=(10 ; 12 ; 2 ; 2 ; 1) \cup(20 ; 24 ; 4 ; 4 ; 0.8)$ We have:

$A_{A, 1}=(10 ; 12 ; 2 ; 2 ; 1)$ and $A_{A, 2}=(20 ; 24 ; 4 ; 4 ; 0.8) \quad \boldsymbol{7}_{A}=\{1 ; 2\}$

The set of scenarios is $\left\{w_{A}\right\}=\{(1 ; 1) ;(1 ; 2) ;(2 ; 1) ;(2 ; 2)\}$

We compute for each scenario $w_{A}$ the quantity $B_{A, j, u}$ which belongs to the period $u$ and the quantity $\bar{B}_{A, v, u}$ which belongs to period $v$ knowing that $A$ belongs to $u$. The resulting scenarios are summarized in Table 5. 
Table 5. Results for the requirement A

\begin{tabular}{|l|l|}
\hline$r_{A} \subseteq 1$ & $B_{A, 1,1}=(10 ; 12 ; 2 ; 2 ; 1)$ \\
\cline { 2 - 2 }$Q_{A} \in \mathbf{7}_{A} \neq 2$ & $B_{A, 2,1}=(20 ; 24 ; 4 ; 4 ; 0.8)$ \\
$\bar{B}_{A, 2,1}=(0 ; 0 ; 0 ; 0 ; 1)$ & \\
\hline$r_{A} \subseteq 2$ & $B_{A, 1,2}=(10 ; 12 ; 2 ; 2 ; 0.5)$ \\
\cline { 2 - 2 }$Q_{A} \in \mathbf{7}_{A} \neq 1$ & $B_{A, 2,2}=(20 ; 24 ; 4 ; 4 ; 0.4)$ \\
$\bar{B}_{A, 1,2}=(0 ; 0 ; 0 ; 0 ; 0.5)$ & \\
\hline
\end{tabular}

\subsubsection{Computation of the gross requirements}

From the various scenarios, a set of gross requirements, which is a set of required quantities for each period on a planning horizon, can be computed.

From Table 4, we generate all the combinations of the requirement scenarios. We have $C=\prod_{o=1}^{O} S_{o x}$ combinations. Let $C$ be the set of these $C$ combinations.

For a combination $c$ of the requirement scenarios, the total required quantity $D_{c, t}$ for a period $t$ is the sum of the required quantities $E_{o, j_{o}, u_{o}, t}$ (equation 14) concerning all the scenarios of requirements $w_{o}$ of this combination belonging to this period $t$ (equation 16).

Thus, for each scenario $w_{o}$ and each period $t$ in $7_{o}$ we first compute $E_{o, j_{o}, u_{o}, t}$. If the requirement $o$ belongs to the considered period $t$, the quantity is equal to $B_{o, j_{o}, u_{o}}$. Else, the quantity is equal to $\bar{B}_{o, t, u_{o}} \cdot B_{o, j_{o}, u_{o}}$ is the quantity indexed by $j_{o}$ of requirement $o$ weighted by the possibility to exist in the period $u_{o}$, and $\bar{B}_{o, t, u_{o}}$ denotes that requirement $o$ belongs to another period than $t$ (quantity=0, possibility denoting that the requirement belong to another period $u_{\mathrm{o}}$ ).

$$
\begin{aligned}
& \forall w_{o}, \forall t \in 7_{o} \\
& E_{o, j_{o}, u_{o}, t}=B_{o, j_{o}, u_{o}} \forall u_{o}=t \\
& E_{o, j_{o}, u_{o}, t}=\bar{B}_{o, t, u_{o}} \forall u_{o} \neq t \\
& \text { with } \\
& \qquad \bar{B}_{o, v, u_{o}}=\left(0 ; 0 ; 0 ; 0 ; \Pi\left(\tau_{o} \in u_{o}\right)\right) \forall v \in \boldsymbol{7}_{o}-\left\{u_{o}\right\} \\
& \forall j_{o} \in\left[1, J_{o}\right], \quad B_{o, j_{o}, u_{o}}=\left(a_{A_{o}, j_{o}} ; b_{A_{o}, j_{o}} ; c_{A_{o}, j_{o}} ; d_{A_{o}, j_{o}} ; h_{A_{o}, j_{o}} \times \Pi\left(\tau_{o} \in u_{o}\right)\right)
\end{aligned}
$$


In order to manage the combinatory explosion of elementary scenarios, the decision maker may select a plausible set of combinations and thus may only consider the combinations for which the possibility is higher than a given value $p$.

The set of combination is then reduced to $C_{\beta}$ (see equation (15)).

$$
\begin{aligned}
& C_{p}=\left\{A_{c}\right\}=\prod_{o=1}^{O}\left\{w_{o}\right\} \forall j_{o} \in J_{o} \text { and } \forall u_{o} \in \mathbf{7}_{o} \\
& w_{o, c}=\left(j_{o, c} ; u_{o, c}\right) \\
& A_{c}=\left\{w_{o, c}\right\} \forall o \in[1, O]
\end{aligned}
$$

Each combination is characterised by a level of possibility (equation 17). The combinations computed are thus classified according to their degree of possibility $P O s_{-} \mathrm{comb}_{c}$.

We compute the gross requirement of the combination $c$ and the total required quantities for the period $\mathrm{t}$ of this combination:

$$
\begin{gathered}
D_{c, t}=\bigoplus_{\substack{o / w_{o, c}=\left(j_{o, c} ; u_{o, c}\right) \in A_{c} \\
P o s_{-} c o m b_{c}=\min _{t}\left(\Pi\left(D_{c, t}\right)\right)(17)}}^{O}\left(E_{o, j_{o, c}, u_{o, c}, t}\right) \forall t, \forall c \\
P_{c}
\end{gathered}
$$

The combinatory is directly linked to the level of imperfection of the requirements, and to the threshold introduced by the decision maker.

Example: let us consider the same requirement $A$

The set of scenarios is $\left\{w_{A}\right\}=\{(1 ; 1) ;(1 ; 2) ;(2 ; 1) ;(2 ; 2)\}$

We compute the quantity for period $\{1 ; 2\}$ of the scenario quantity $w_{A}$ (in this case

$$
\begin{aligned}
& \left.E_{A, j, u, 1} \text { and } E_{A, j, u, 2}\right) \\
& E_{A, 1,1,1}=B_{A, 1,1} ; E_{A, 2,1,1}=B_{A, 2,1} ; E_{A, 1,2,2}=B_{A, 1,2 ;} E_{A, 2,2,2}=B_{A, 2,2} \\
& E_{A, 1,1,2}=\bar{B}_{A, 2,1} ; E_{A, 2,1,2}=\bar{B}_{A, 2,1} ; E_{A, 1,2,1}=\bar{B}_{A, 1,2 ;} E_{A, 2,2,1}=\bar{B}_{A, 1,2}
\end{aligned}
$$

Then, we compute the gross requirements:

$$
\begin{aligned}
& D_{1,1}=E_{A, 1,1,1}=(10 ; 12 ; 2 ; 2 ; 1) ; \quad D_{1,2}=E_{A, 1,1,2}=(0 ; 0 ; 0 ; 0 ; 1) \\
& D_{2,1}=E_{A, 1,2,1}=(0 ; 0 ; 0 ; 0 ; 0.5) ; \quad D_{2,2}=E_{A, 1,2,2}=(10 ; 12 ; 2 ; 2 ; 0.5) \\
& D_{3,1}=E_{A, 2,1,1}=(20 ; 24 ; 4 ; 4 ; 0.8) ; \quad D_{3,2}=E_{A, 2,1,2}=(0 ; 0 ; 0 ; 0 ; 0.8)
\end{aligned}
$$




$$
D_{4,1}=E_{A, 2,2,1}=(0 ; 0 ; 0 ; 0 ; 0.4) ; \quad D_{4,2}=E_{A, 2,2,2}=(20 ; 24 ; 4 ; 4 ; 0.4)
$$

\section{ILLUSTRATIVE EXAMPLE}

In this example, we consider four requirements concerning material C. Each requirement has its origin in four different products $\mathrm{P} 1, \mathrm{P} 2, \mathrm{P} 3$ and $\mathrm{P} 4, \mathrm{C}$ being one of their components. These requirements are imperfectly known. The time horizon is 28 days and starts at day 0 . Each period is composed of 7 days. The gross requirements of material $\mathrm{C}$ has to be computed.

The following qualitative information on each requirement is available (depending for instance on the schedule of assembly):

Requirement 1:

- Two quantities are possible 300 (very possible) and 600 (could be possible). These quantities are given at \pm 20 units

- The requirement date is 20 . This date is given at \pm 2 days

Requirement 2:

- The most possible quantity is between 400 and 450 , but the requirement is not totally sure. This quantity is given at \pm 10 units

- The requirement date is between 14 and 16 and this date is given at \pm 2 days

Requirement 3:

- The most possible quantity required is between 350 and 360 . This quantity is given at \pm 10 units

- Two dates are possible:

- The most possible: around 5 (given at \pm 1 days)

- The less possible: around 15 (given at \pm 3 days)

Requirement 4:

- The most possible requirement quantity is between 600 and 620 . This quantity is given at \pm 20 units

- The most possible date is between 25 and 26 ; it is possible to need this quantity up to two days before, but not later than the most possible date.

These pieces of information are represented in Figures 8 and 9. 
Requirement 1

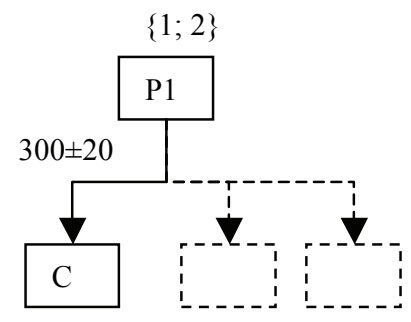

Requirement 3

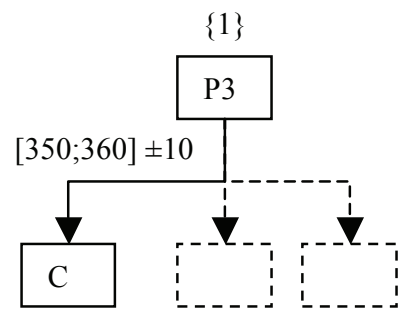

Requirement 2

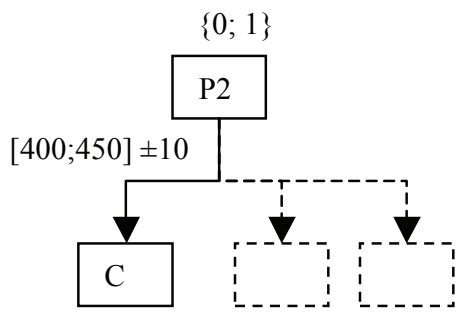

Requirement 4

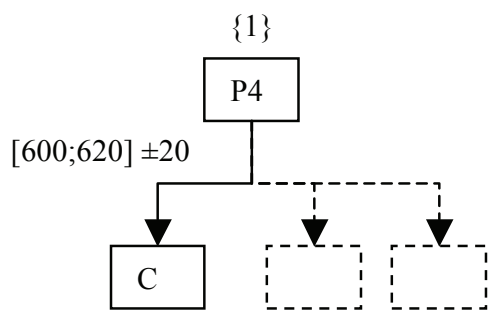

Figure 8. Information on quantities from the expert

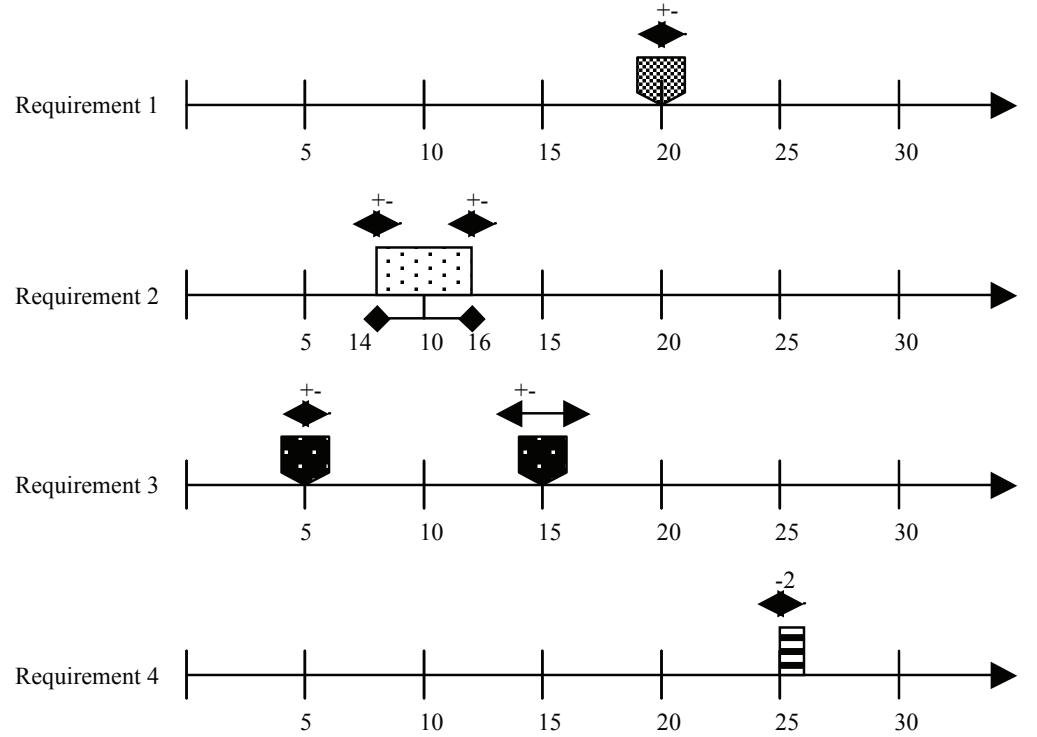

Figure 9. Information on dates from the expert

\subsection{Possibilistic model of the ill-known requirements}

The first step of the method is to build the possibilistic models describing each requirement, on the base of their "expert" description. The result, obtained according to the principles described in section 4, are given for Requirements 1 and 2 in Table 6 and 7 (requirements 3 and 4 are similar). 
Table 6. Model for Requirement 1

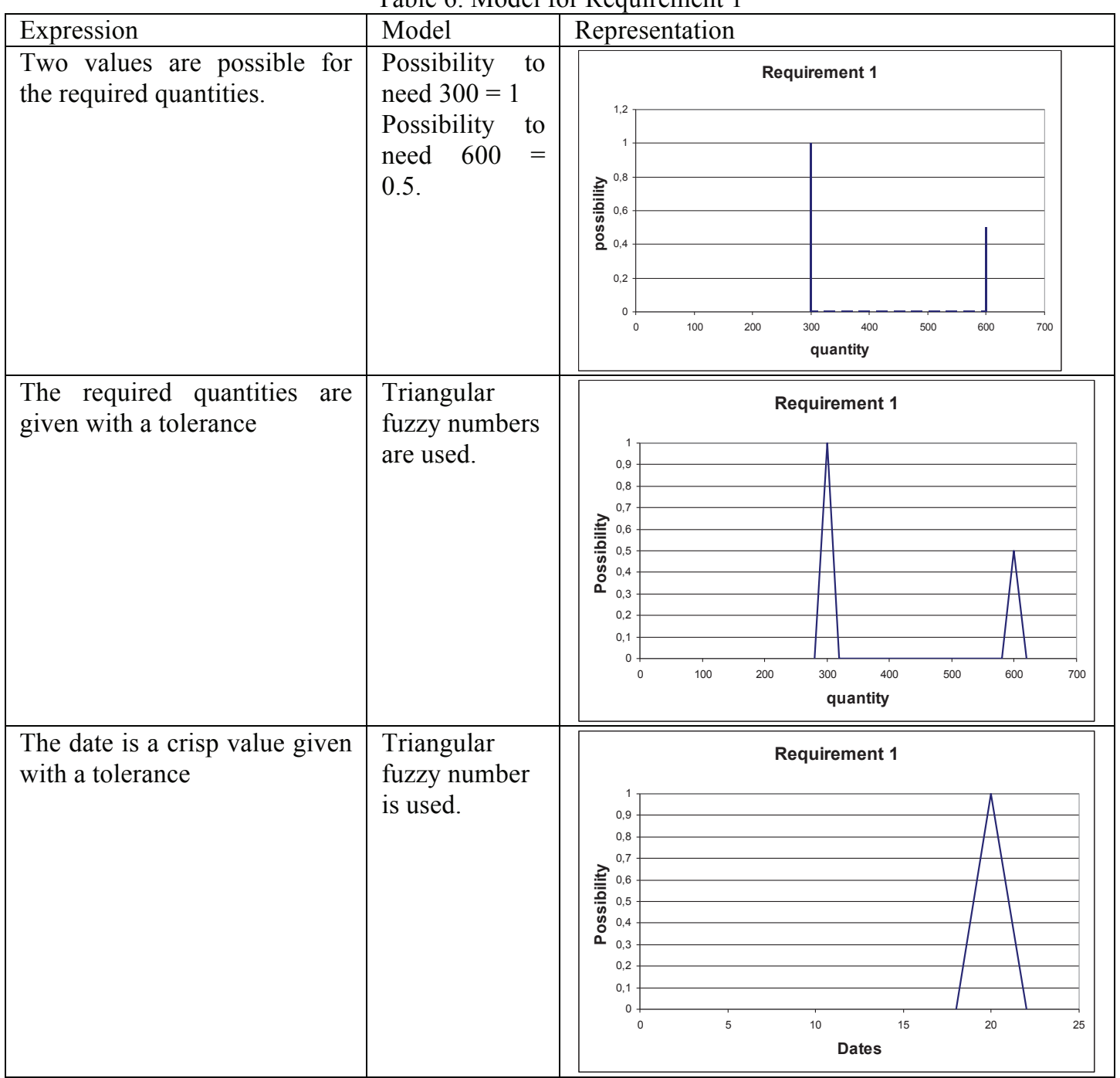


Table 7. Model for Requirement 2

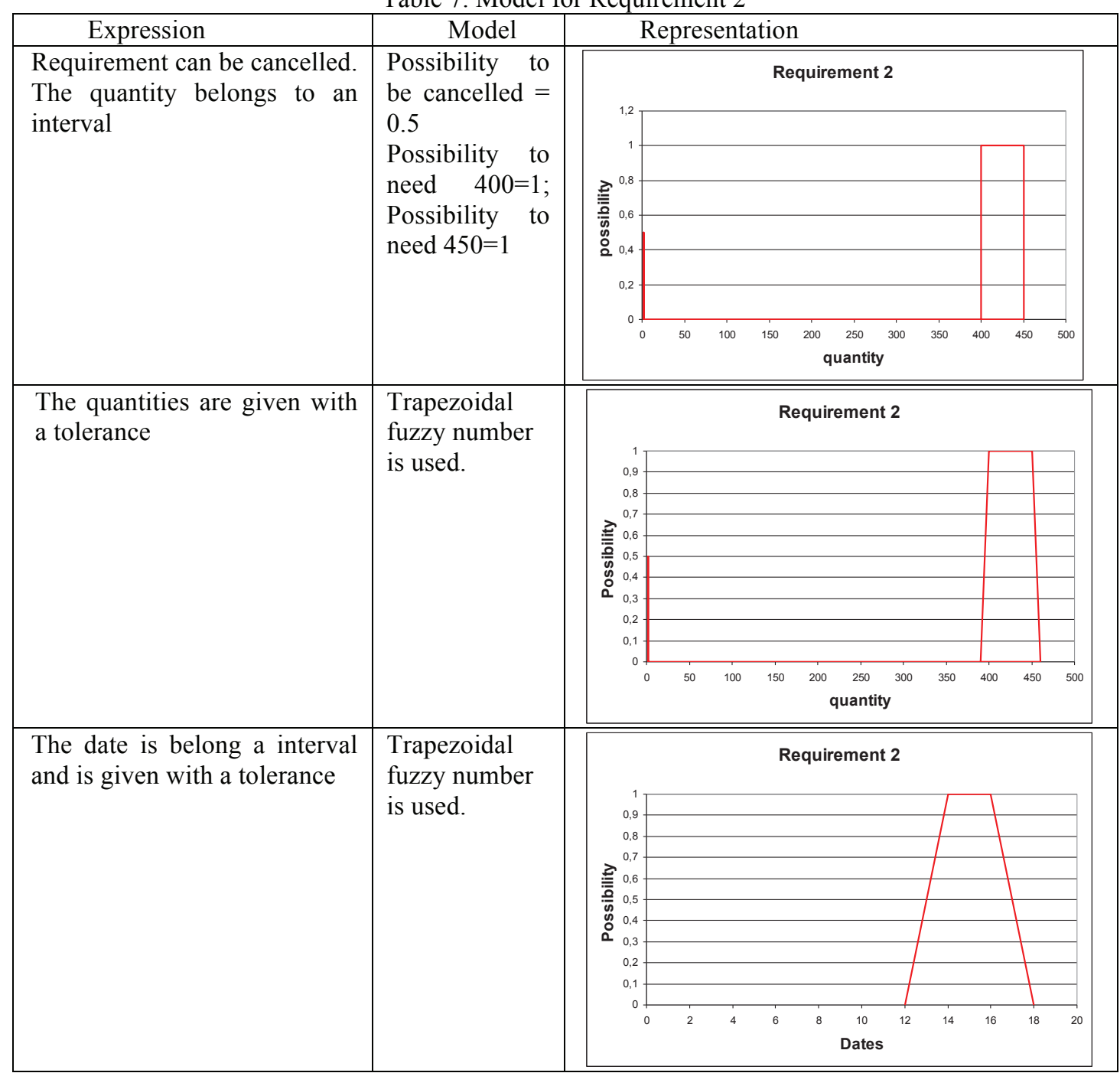

Table 8 summarizes the model whereas Figures 10 and 11 represent graphically the models of the required quantities. Figure 12 summarizes the models of the requirements dates (black lines represent the periods).

Table 8. Requirements

\begin{tabular}{|l|l|l|}
\hline & Quantity & Requirement date \\
\hline$r_{1}$ & $(300 ; 300 ; 20 ; 20 ; 1) \mathrm{U}(600 ; 600 ; 20 ; 20 ; 0.5)$ & $(20 ; 20 ; 2 ; 2 ; 1)$ \\
\hline$r_{2}$ & $(400 ; 450 ; 10 ; 10 ; 1) \mathrm{U}(0 ; 0 ; 0 ; 0 ; 0.5)$ & $(14 ; 16 ; 2 ; 2 ; 1)$ \\
\hline$r_{3}$ & $(350 ; 360 ; 10 ; 10 ; 1)$ & $(5 ; 5 ; 1 ; 1 ; 1) \mathrm{U}$ \\
& & $(15 ; 15 ; 3 ; 3 ; 0.5)$ \\
\hline$r_{4}$ & $(600 ; 620 ; 20 ; 20 ; 1)$ & $(25 ; 26 ; 2 ; 0 ; 1)$ \\
\hline
\end{tabular}



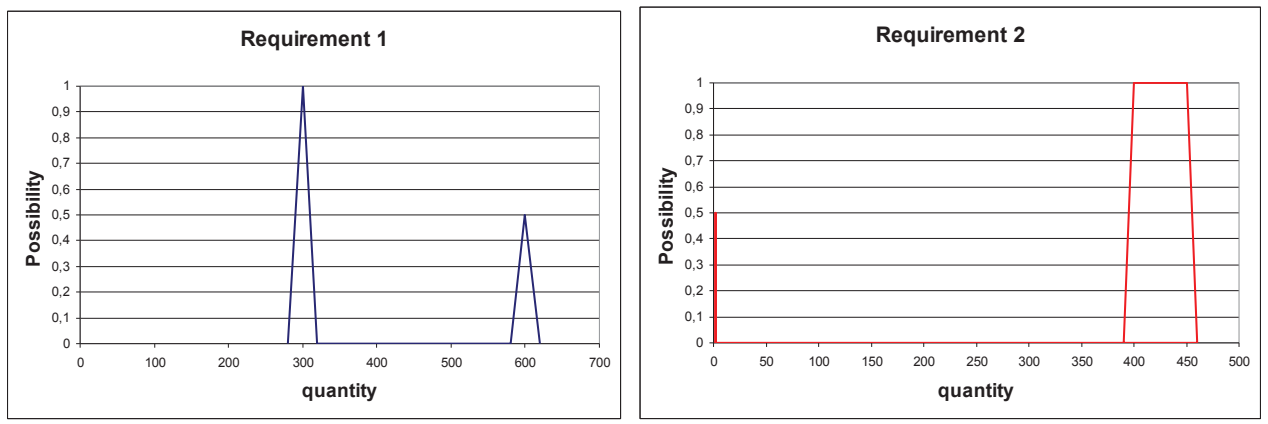

Figure 10. Representation of the quantities for requirements 1 and 2
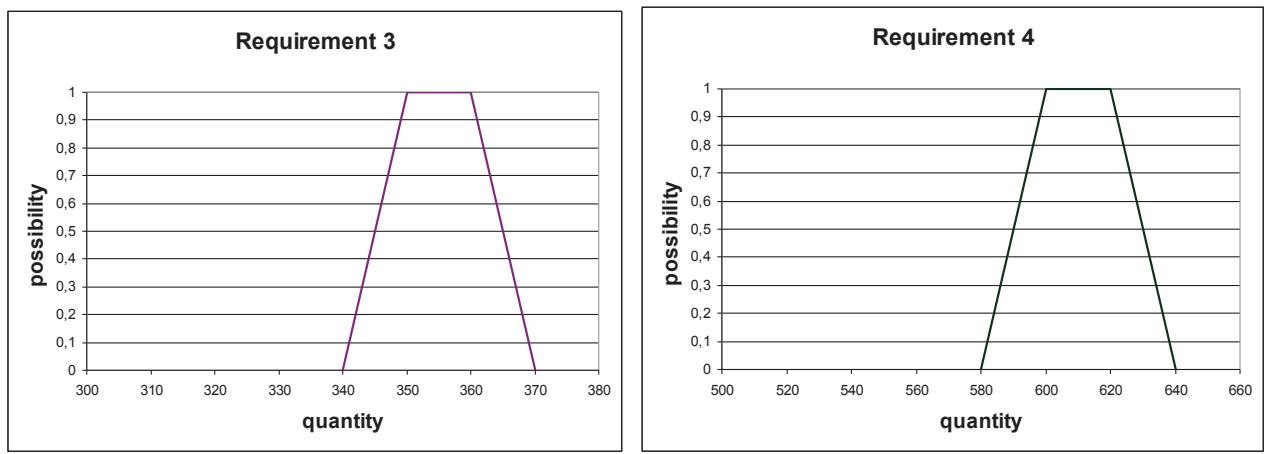

Figure 11. Representation of the quantities for requirements 3 and 4

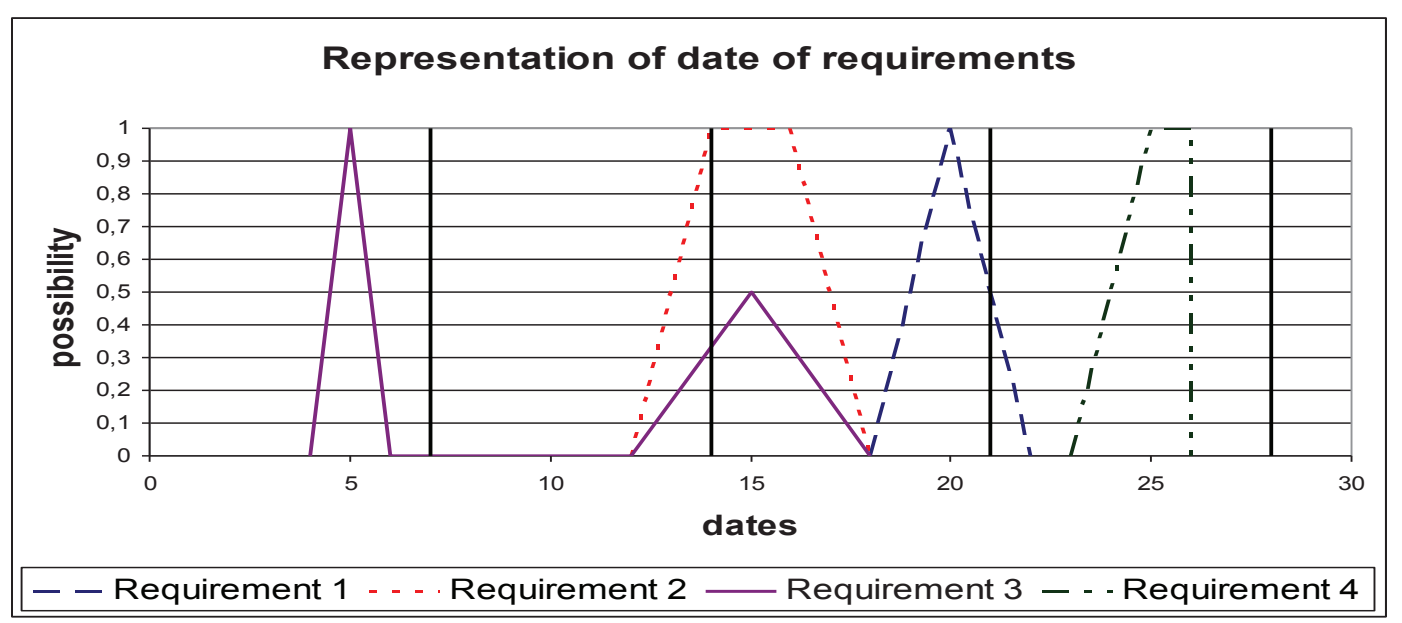

Figure 12. Representation of the dates of requirement

\subsection{Material Requirement Planning}

\subsubsection{Design of requirement scenarios}

The next step consists in building the scenarios according to the requirements belonging to the different time periods of the gross requirement horizon. 7 being the set of the possible periods for requirement $o$, the level of possibility that each requirement belongs to the different periods has to be computed (Table 9). 
Table 9. Possibility than the requirements belong to the different periods

\begin{tabular}{|l|l|l|l|l|}
\hline & Requirement 1 & Requirement 2 & Requirement 3 & Requirement 4 \\
\hline Period 1 & $\Pi\left(\tau_{1} \in 1\right)=0$ & $\Pi\left(\tau_{2} \in 1\right)=0$ & 1 & 0 \\
\hline Period 2 & $\Pi\left(\tau_{1} \in 2\right)=0$ & 1 & 0.33 & 0 \\
\hline Period 3 & 1 & 1 & 0.5 & 0 \\
\hline Period 4 & 0.5 & 0 & 0 & 1 \\
\hline
\end{tabular}

From Table 9, we determine the set of possible periods for each requirement $\boldsymbol{7}_{1}=\{3 ; 4\}, \boldsymbol{7}_{2}=\{2 ; 3\}$, $\boldsymbol{Z}_{3}=\{1 ; 2 ; 3\}$ and $\boldsymbol{\gamma}_{4}=\{4\}$.

Then, we can build the different scenarios for each requirement (Tables 10 to 13):

Table 10. Results for the requirement 1

\begin{tabular}{|l|l|}
\hline$r_{1} \subseteq 3$ & $B_{1,1,3}=(300 ; 300 ; 20 ; 20 ; 1)$ \\
\cline { 2 - 2 }$Q_{1} \in \mathbf{Z}_{1} \neq 3$ & $B_{1,2,3}=(600 ; 600 ; 20 ; 20 ; 0.5)$ \\
$\bar{B}_{1,3,4}=(0 ; 0 ; 0 ; 0 ; 1)$ & \\
\hline$r_{1} \subseteq 4$ & $B_{1,1,4}=(300 ; 300 ; 20 ; 20 ; 0.5)$ \\
\cline { 2 - 2 }$Q_{1} \in \mathbf{Z}_{1} \neq 4$ & $B_{1,2,4}=(400 ; 400 ; 20 ; 20 ; 0.25)$ \\
$\bar{B}_{1,4,3}=(0 ; 0 ; 0 ; 0 ; 0.5)$ & \\
\hline
\end{tabular}

Table 11. Results for the requirement 2

\begin{tabular}{|l|l|}
\hline$r_{2} \subseteq 2$ & $B_{2,1,2}=(400 ; 450 ; 10 ; 10 ; 1)$ \\
\cline { 2 - 2 }$Q_{2} \in \mathbf{Z}_{2} \neq 2$ & $B_{2,2,2}=(0 ; 0 ; 0 ; 0 ; 0.5)$ \\
$\bar{B}_{2,2,3}=(0 ; 0 ; 0 ; 0 ; 1)$ & \\
\hline$r_{2} \subseteq 3$ & $B_{2,1,3}=(400 ; 450 ; 10 ; 10 ; 1)$ \\
\cline { 2 - 2 }$Q_{2} \in \mathbf{Z}_{2} \neq 3$ & $B_{2,2,3}=(0 ; 0 ; 0 ; 0 ; 0.5)$ \\
$\bar{B}_{2,3,2}=(0 ; 0 ; 0 ; 0 ; 1)$ & \\
\hline
\end{tabular}

Table 12. Results for the requirement 3

\begin{tabular}{|l|l|}
\hline$r_{3} \subseteq 1$ & $B_{3,1,1}=(350 ; 360 ; 10 ; 10 ; 1)$ \\
$Q_{3} \in \mathbf{7}_{3} \neq 1$ & \\
$\bar{B}_{3,1,2}=\bar{B}_{3,1,3}=(0 ; 0 ; 0 ; 0 ; 1)$ & \\
\hline$r_{3} \subseteq 2$ & $B_{3,1,2}=(350 ; 360 ; 10 ; 10 ; 0.33)$ \\
$Q_{3} \in \mathbf{7}_{3} \neq 2$ & \\
$\bar{B}_{3,2,1}=\bar{B}_{3,2,3}=(0 ; 0 ; 0 ; 0 ; 0.33)$ & \\
\hline$r_{3} \subseteq 3$ & $B_{3,1,2}=(350 ; 360 ; 10 ; 10 ; 0.5)$ \\
$Q_{3} \in \mathbf{7}_{3} \neq 3$ & \\
$\bar{B}_{3,3,1}=\bar{B}_{3,3,2}=(0 ; 0 ; 0 ; 0 ; 0.5)$ & \\
\hline
\end{tabular}

Table 13. Results for the requirement 4

\begin{tabular}{|l|l|}
\hline$r_{4} \subseteq 4$ & $B_{4,1,4}=(600 ; 620 ; 20 ; 20 ; 1)$ \\
$Q_{4} \in \mathbf{7}_{4} \neq 4$ & \\
\hline
\end{tabular}




\subsubsection{Computation of the gross requirements}

From Tables 10 to 13, the different gross requirements are obtained for some combinations of the requirement scenarios (Figure 13). There are 48 possible gross requirements, but only the gross requirements with level of possibility 1 are computed, so that the less possible gross requirement which could happen in the worst case: possibility $=0.25$ (Table 14 and Table 15).

Table 14. Combinations

\begin{tabular}{|l|l|l|l|l|}
\hline & Requirement 1 & Requirement 2 & Requirement 3 & Requirement 4 \\
\hline \multirow{2}{*}{$\begin{array}{l}\text { Gross } \\
\text { requirements } \\
\text { combination 1 }\end{array}$} & $r_{1} \subseteq 3 \& A_{1}$ & $r_{2} \subseteq 2 \& A_{1}$ & $r_{3} \subseteq 1 \& A_{1}$ & $r_{4} \subseteq 4 \& A_{1}$ \\
\cline { 2 - 5 } $\begin{array}{l}\text { Gross } \\
\text { requirements } \\
\text { combination 2 }\end{array}$ & $r_{1} \subseteq 3 \& A_{1}$ & $r_{2} \subseteq 3 \& A_{1}$ & $r_{3} \subseteq 1 \& A_{1}$ & $(600 ; 20 ; 20 ; 1)$ \\
\cline { 2 - 5 } $\begin{array}{l}\text { Gross } \\
\text { requirements } \\
\text { combination 3 }\end{array}$ & $\left.r_{1} \subseteq 400 ; 300 ; 20 ; 20 ; 1\right)$ & $(400 ; 450 ; 10 ; 10 ; 1)$ & $(350 ; 360 ; 10 ; 10 ; 1)$ & $(600 ; 620 ; 20 ; 20 ; 1)$ \\
\cline { 2 - 5 } & $(400 ; 400 ; 20 ; 20 ; 0.25)$ & $(0 ; 0 ; 0 ; 0 ; 0.5)$ & $(350 ; 360 ; 10 ; 10 ; 0.33)$ & $(600 ; 620 ; 20 ; 20 ; 1)$ \\
\hline
\end{tabular}

Table 15. Gross requirement for a combination

\begin{tabular}{|l|l|l|l|l|}
\hline & Period 1 & Period 2 & Period 3 & Period 4 \\
\hline Pos_comb $1=1$ & $(350 ; 360 ; 10 ; 10 ; 1)$ & $(400 ; 450 ; 10 ; 10 ; 1)$ & $(300 ; 300 ; 20 ; 20 ; 1)$ & $(600 ; 620 ; 20 ; 20 ; 1)$ \\
\hline Pos_comb $2=1$ & $(350 ; 360 ; 10 ; 10 ; 1)$ & $(0 ; 0 ; 0 ; 0 ; 1)$ & $(700 ; 750 ; 30 ; 30 ; 1)$ & $(600 ; 620 ; 20 ; 20 ; 1)$ \\
\hline Pos_comb $3=0.25$ & $(0 ; 0 ; 0 ; 0 ; 0.33)$ & $(350 ; 360 ; 10 ; 10 ; 0.33)$ & $(0 ; 0 ; 0 ; 0 ; 0.33)$ & $(985 ; 1035 ; 25 ; 25 ; 0.25)$ \\
\hline
\end{tabular}
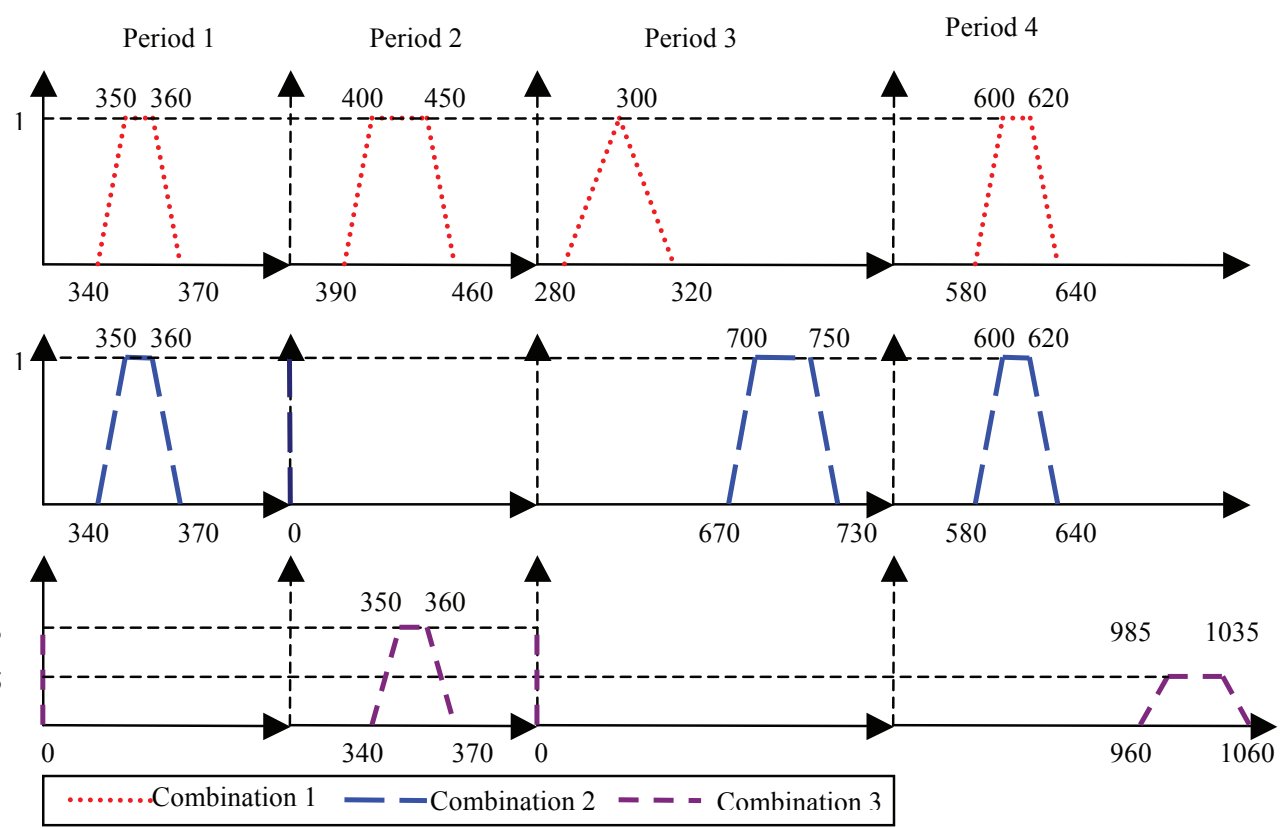

Figure 13. Fuzzy gross requirements 
Now, let us consider that the four requirements have been considered as crisp for making possible a "classical" gross requirement calculation. In that case, the four requirements will be certainly considered as follows (see summary in Table 16):

Requirement 1: quantity 300, date 20; Requirement 2: quantity 425, date 15 ; Requirement 3: 355 , date 5; Requirement 4: 610, date 25. Thus the crisp gross requirement is given in Table 16.

\begin{tabular}{|c|c|c|c|c|}
\hline Table 16. "Crisp" gross requirement \\
\hline period & 1 & 2 & 3 & 4 \\
\hline quantity & 355 & 0 & 725 & 610 \\
\hline
\end{tabular}

It can be seen that the "crisp" scenario of Table 16, obtained by neglecting any knowledge on the imprecision of the input information, is close to combination 2. Therefore, a first result is that our method is consistent with a "good sense" defuzzification obtained by considering only the most plausible cases. What is more important is that another scenario, obtained with combination 1 , has the same possibility $(=1)$ : as a matter of fact, there is a possibility equal to one that some requirements are also present in period 2, and as a consequence that the gross requirements are relatively balanced on the four considered periods. In addition, it can be seen that there are slight possibilities $(0.33$ and 0.25$)$ that the gross requirements are completely unbalanced, with a quantity around 350 during period 2 and a huge quantity, around 1000, during period 4.

It is so clear that the method may allow to obtain a much more informative set of possible situations, together with an estimation of their possibility of occurrence. On that base, the decision maker is able to make a really "informed" decision, considering not only the most plausible case but also an estimation of the risk taken regarding to the possibility of occurrence of other situations.

\section{Conclusion}

Through a literature review, we have shown that the idea to model an imprecise demand on final products using possibility theory has sometimes been considered, but that the practical way for dealing with such a demand in the first steps of the MRP method (Material Requirement Planning) has not yet been fully explored. However, this step is the base for generating a supply plan for the upstream partners of the supply chain, which should take benefit from more precise information.

In this paper, uncertainty and imprecision on the requirements have been analysed and a model allowing to take them into account has been proposed. Based on this model, a method has been 
suggested for modelling uncertain gross requirements (describing plausible quantities by period). The result stresses that the resulting uncertain quantity which is required is not a simple fuzzy set, but describes a set of situations, which is much more informative than the result obtained by considering only the most plausible requirements. Indeed, this model does not lose any information on the relation between period and quantity.

As a following step, two different options are possible: the decision maker may choose a supply plan after assessing its feasibility, and may compute the risk taken (shortage or excess of inventories) if other situations occur. In order to do this, he can defuzzify the gross requirement before sending it to his supplier. The second solution is to transmit the set of the most plausible supply plans to the supplier as an element for negotiation. Indeed, the described situations are a good starting point for assessing how the risk taken by preparing a situation more than another can be shared between the two partners.

In this article, the incompleteness of the requirements has not been considered. Considering this other type of imperfection is an interesting perspective for the study, since the knowledge on the requirements may be incomplete for far periods. In that case, any evaluation of the required quantity linked to forecasts could be false. An incompleteness factor could be added to the requirements already known through long term contracts in order to address this problem.

Finally, fuzzy demands can be considered in other cases, such as economic production quantity models (Lee and Yao, 1997), inventory control (Petrovic et al., 2008) or optimal inventory (Chiang and Wenkai, 2000), also requiring a demand defined by quantities by period. As a perspective, the integration of our model in those methods could be another interesting issue.

Acknowledgements: This study has been performed with the support of Région Midi-Pyrénées and of the University of Toulouse.

\section{REFERENCES}

Aliev, R.A., et al., 2007. Fuzzy-genetic approach to aggregate production-distribution planning in supply chain management. Information Sciences, 177 (20), 4241-4255.

Balasubramanian, J. and Grossmann, I.E., 2003. Scheduling optimization under uncertainty an alternative approach. Computers and Chemical Engineering, 27, 469-490.

Baykasoglu, A. and Göçken, T., 2008. A review and classification of fuzzy mathematical programs. Journal of Intelligent \& Fuzzy Systems, 19 (3), 205-229.

Bellman, R. and Zadeh, L.A., 1970. Decision making in a fuzzy environment. Management Science, 17, 141-164.

Bouchon-Meunier B., 1995. La logique floue et ses applications, Addison-Wesley.

Chen, C.-T. and Huang, S.-F., 2006. Order-fulfillment ability analysis in the supply-chain system with fuzzy operation times. International Journal of Production Economics, 101, 185-193. 
Chiang, K. and Wen-kai, H., 2000. A single-period Inventory model with fuzzy demand. Computers and Mathemarics with applications, 43(6), 841-848.

Delgado, M. and Kacprzyk J., 1994. Fuzzy Optimization: "Recent Advances". Physica Verlag,Heidelberg.

Dubois, D. and Prade, H., 1988. Possibility Theory, Plenum Press New York.

Dubois, D. , Prade, H. and Sabbadin, R., 2001. Decision-theoretic foundations of qualitative possibility theory. European Journal of Operational Research, 128 (3), 459-478

Dubois, D., Fargier, H. and Fortemps, P., 2003. Fuzzy scheduling: Modelling flexible constraints vs. coping with incomplete knowledge. European Journal Operational Research, 147 (2), 231252.

Dubois, D. and Prade, H., 2006. Représentations formelles de l'incertain et de l'imprécis. In : Hermès - Lavoisier, eds. Concepts et méthodes pour l'aide à la décision 1, 11-165.

Fargier, H. and Thierry, C., 2000. The use of Possibilistic Decision Theory in Manufacturing, Planning and Control: Recent Results in Fuzzy Master Production Scheduling. In: R. Slowinski and M. Hapke, eds. Studies in fuzziness and soft computing. Spingler-Verlag, 36, 45-59.

Galasso, F. Mercé, C. and Grabot, B., 2009. Decision Support for Supply Chain Planning under uncertainty. International Journal of Systems Science, 39 (7), 667-675.

Grabot, B., et al., 2005. Integration of uncertain and imprecise orders in the MRP method. Journal of intelligent manufacturing, 16 (2). 215-234

Grzegorzewski, P., 2008. Trapezoidal Approximations of Fuzzy Numbers preserving the expected interval: Algorithms and properties. Fuzzy Sets and Systems, 159 (11), 1354-1364.

Ireland, R. and Crum, C., 2005. Supply chain Collaboration: how to implement CPFR ${ }^{\circledR}$ and other best collaborative practices, Integrated Business Management series and APICS

Jamalnia, A. and Soukhakian, M.A., 2009. A hybrid fuzzy goal programming approach with different goal priorities. Computers \& Industrial Engineering, 56 (4), 1474-1486.

Kacprzyk, J. and Orlovski, S.A., 1987. Fuzzy optimization and mathematical program-ming: a brief introduction and survey. In: J. Kacprzyk and S.A. Orlovski eds. Optimization Models Using Fuzzy Sets and Possibility Theory, Boston: Reidel, 50-72.

Lee H.M, and Yao J.S., 1997. Economic production quantity for fuzzy demand quantity and fuzzy production quantity. European Journal of Operational Research, 109 (1), 203-211.

Liang, T.F., 2008. Fuzzy multi-objective production/distribution planning decisions with multi-product and multi-time period in a supply chain. Computers \& Industrial Engineering, 55 (3), 676694.

Liu, B., 2009. Theory and practice of uncertain programming, New York: Physica-Verlag.

Lan, Y.F., Liu, Y-K. and Sun G-J., 2009. Modeling fuzzy multi-period production planning and sourcing problem with credibility service levels, Journal of Computational and Applied Mathematics, 231 (1), 208-221.

Marques, G., et al., 2008. Vendor Managed Inventory, from concept to processes, for an unified view. International Conference on Information Systems, Logistics and Supply Chain, 28-30 May 2008 Madison. University of Wisconsin, 536-546.

Mauris, G., 2008. Inferring a Possibility Disdribution from Very few Measurements. In: D. Dubois et al. eds. Advances in soft computing, 48, 92-99.

Mula, J., Polera, R. and Garcia-Sabater, J.P., 2007. Material Requirement Planning with fuzzy constraints and fuzzy coefficients, Fuzzy Sets and Systems, 158 (7), 783 - 793.

Niu, J. and Dartnall, J., 2008. Application of Fuzzy MRP II in fast moving consumer goods manufacturing industry. Proceedings of the $40^{\text {th }}$ Conference on Winter Simulation, $07-10$ December 2008 Miami, 1939-1945.

Peidro, D., et al., 2009. Fuzzy optimization for supply chain planning under supply, demand and process uncertainties. Fuzzy Sets and Systems, 160 (18), 2640-2657.

Petrovic, D., et al., 2008. Coordinated control of distribution supply chains in the present of fuzzy customer demand. European journal of Operational Research, 185 (1), 146-158.

Sun, G.J. and Liu, Y.K., 2008. Fuzzy Minimum risk material procurement planning problem, $4^{\text {th }}$ International Conference on Natural Computation, 18 - 20 October 2008, 7, 629-633.

Zadeh, L.A., 1978. Fuzzy sets as a basis for a theory of possibility. Fuzzy Sets and Systems, 1, 3-28.

Zhao, X. and Xie, J., 1998. Multilevel lot-sizing heuristics and freezing the master production schedule in material requirements planning systems. Production Planning \& Control, 9 (4), 371-384. 